\title{
Novel, self-made and cost-effective technique for closed-incision negative pressure wound therapy
}

\author{
Dominik A. Walczak, Maciej Grajek, Marcin Zeman, Tomasz Pałka, Mathias Kalkum, Mirosław Dobrut, Piotr \\ Drozdowski, Rafał Ulczok, Karolina Donocik, Adam Maciejewski, Łukasz Krakowczyk
}

\section{TOOLS AND TECHNIQUES}

\begin{abstract}
Background: It has been suggested that applying the negative pressure wound therapy (NPWT) to a closed surgical incision may hasten the healing of the incision and decrease the incidence of wound healing complications. The goal of this study is to present the new idea of a simple, self-made, low-cost wound vacuum dressing for closed-incision NPWT that may become an alternative to currently manufactured medical industry products.

Method: We designed a simple dressing for closed-incision NPWT from gauze pads, polyurethane adhesive film, stoma paste, and a drain tube. Negative pressure was created using a standard $50 \mathrm{ml}$ syringe connected to the drain. First, the dressing was applied to the wound model and on the healthy volunteer. Finally, the dressing was applied to 10 patients after low anterior rectal resection. The vacuum dressing was left in place for 3 days, then changed and placed once more for the next 3 days.

Results: We did not observe any adverse effects associated with the dressing. All postoperative wounds healed properly. 18 out of 20 dressings were still air-tight $72 \mathrm{~h}$ post-placement.

Conclusions: This simple, self-made dressing for NPWT is safe and effective and may decrease the wound infection rate. However future studies are needed to confirm that hypothesis.
\end{abstract}

Keywords-NPWT; vacuum-assisted closure; surgical site infection; closed incision negative-pressure wound therapy

\section{INTRODUCTION}

$\mathbf{N}$ EGATIVE Pressure Wound Therapy (NPWT) is an accepted way of treating chronic wounds or supporting skin grafts. However, there is an emerging body of literature describing a novel application of NPWT to surgical incisions healing by primary intention. It has been suggested that applying NPWT to a closed surgical incision may hasten the healing of the incision and decrease the incidence of complications, such as infection or wound dehiscence ${ }^{1}$ However, these systems are quite expensive, making their usage limited in developing countries.

This paper presents a novel method of simple, self-made, low-cost wound vacuum dressing that may become an alternative to commercially available medical products.

Manuscript received 29.11.2019; revised 05.03.2020. This work did not receive any financial support.

Author affiliations: Department of Oncological and Reconstructive Surgery, Maria Sklodowska-Curie Institute-Oncology Center, Gliwice, Poland , (DW, MG, MZ, TP, MD, PD, RU, KD, AM, ŁK); Department of General and Visceral Surgery, Tirschenreuth County Hospital, Tirschenreuth, Germany , (MK)

*Correspondence to: Dominik Walczak: dr.dominikwalczak@gmail.com
Equipment necessary for dressing application:

1) $10 \times 10 \mathrm{~cm}$ gauze pads

2) dressing impregnated with paraffin wax (e.g., Grasolind, Jelonet)

3) drape (polyurethane adhesive film - e.g., Hydrofilm, PAUL HARTMANN AG, Germany)

4) $50 \mathrm{ml}$ syringe with a luer lock

5) stoma paste

6) drain - intravenous extension set with a clamp and a luer access split-septum

7) peripheral venous catheter (PVC) film dressing

\section{DRESSING APPLICATION TECHNIQUE}

The dressing should be applied at the end of the surgical procedure.

1) Dry the peri-wound skin.

2) Cut $5 \mathrm{~cm}$ wide strips of ointment dressing (e.g., Grasolind, etc.) and place it over the wound (half the size of the gauze pad)

3) Fold the gauze pads once and cover the wound, then similarly create the second layer.

4) Measure and trim the drape to cover the gauze with an additional border of $2-3 \mathrm{~cm}$

5) Apply the drape over the gauze, including about $2-3$ $\mathrm{cm}$ of the surrounding skin (Fig. 1 .

6) Create a small aperture $(0.5-1 \mathrm{~cm}$ in diameter $)$ in the drape at the upper pole of the dressing. Create a space between two layers of folded gauze pads.

7) Insert the drain into created space.

8) Cover the aperture in the drape (where the drain enters the dressing) with the stoma paste.

9) Adhere 2 PVC film dressings over the aperture and around the drain to provide airtightness (Fig. 2).

10) Evacuate residual air with a syringe to create negative pressure.

The vacuum dressing was left in place for 72 hours. The wound exudate was collected in the gauze (Fig. 3). Initially, the dressing was applied to the wound model and on the healthy volunteer to measure the negative pressure by a liquid column depending on the size of the wound and the amount of air which was removed with a syringe (Fig. 4) (Tab. I). A self-made liquid column manometer filled with distilled water was used to measure the pressure. Experimental assays were 


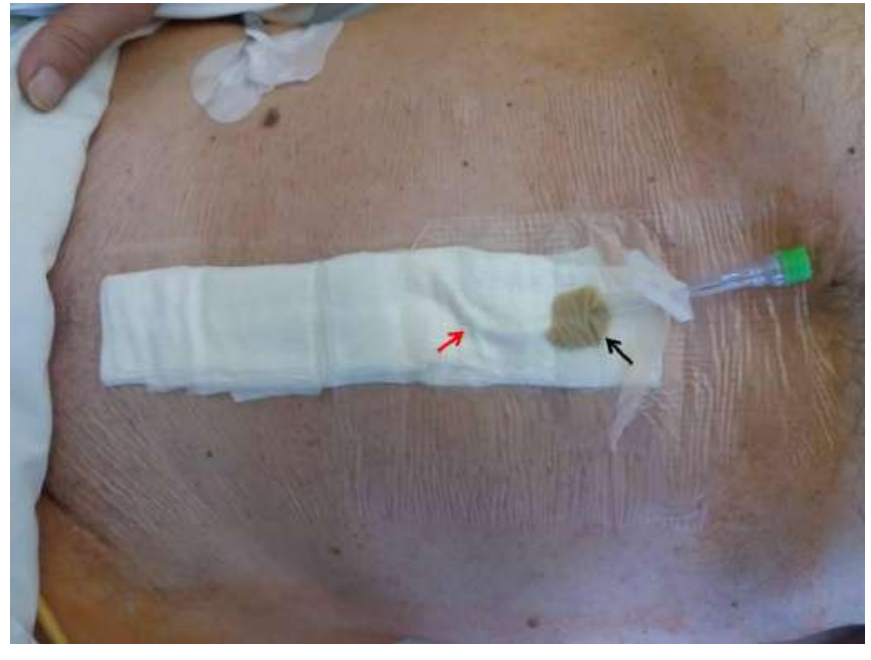

Figure 1. Dressing applied to the wound after low anterior rectal resection. Black arrow - stoma paste covering the aperture were drain (i.e., intravenous extension set) enters the dressing; red arrow — drain between the two layers of a gauze pad.

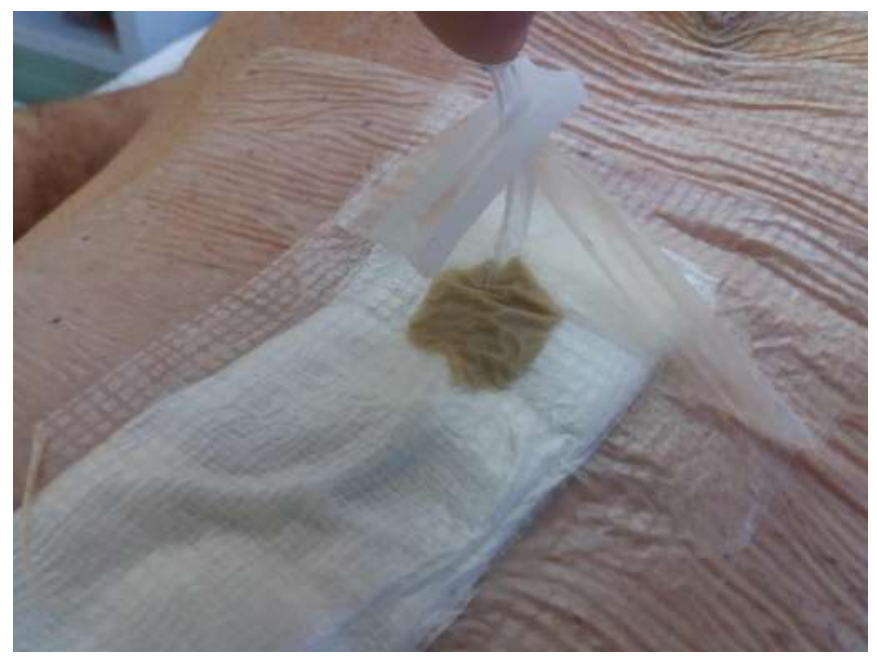

Figure 2. Two PVC film dressings adhered together over the orifice and around the drain to provide airtightness.

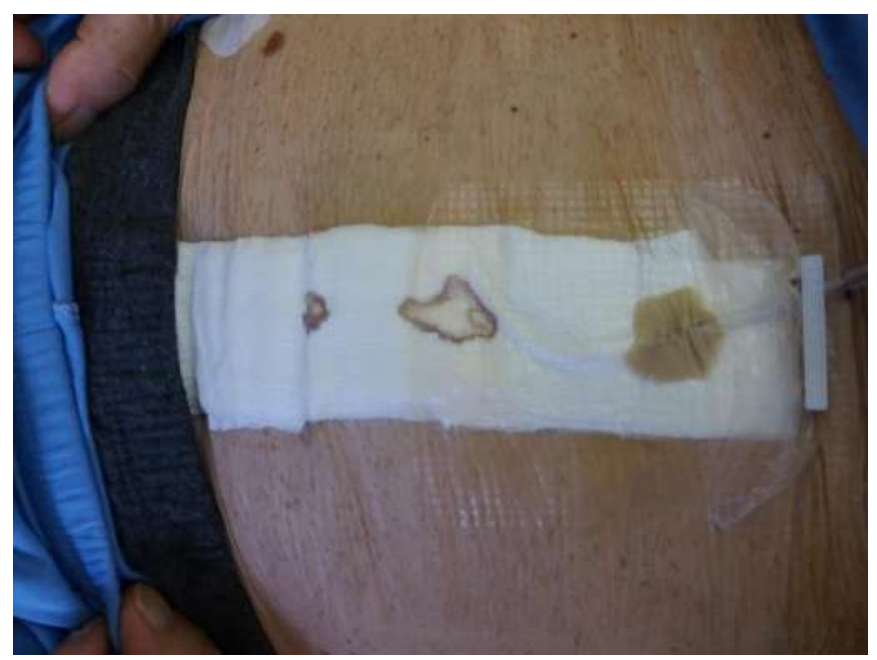

Figure 3. The vacuum dressing after 72 hours.

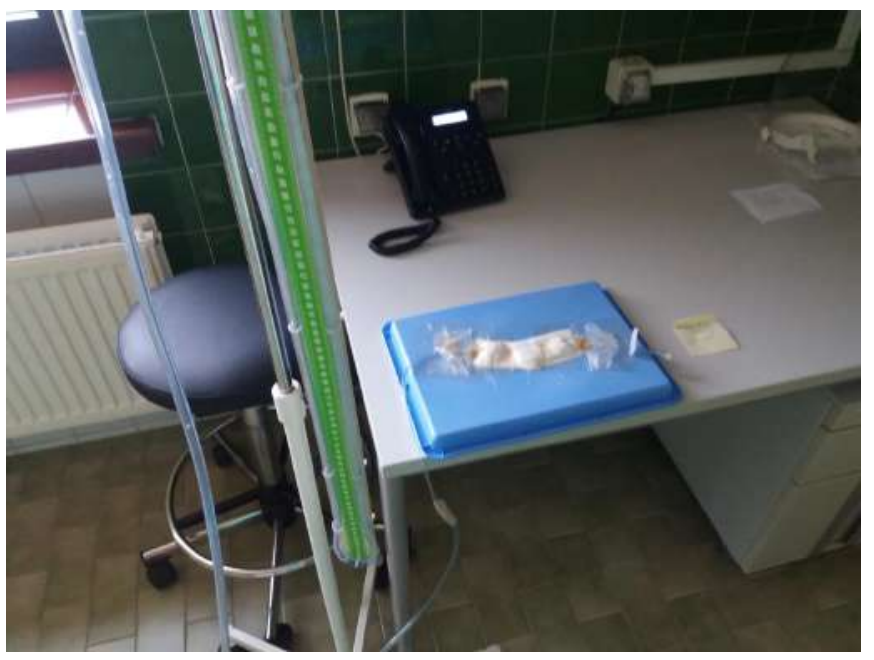

Figure 4. Dressing applied to the wound model with a liquid column to measure negative pressure.

Table I

THE TABLE SHOWS THE APPROXIMATE AMOUNT OF AIR THAT SHOULD BE REMOVED WITH A SYRINGE TO ACHIEVE A CERTAIN NEGATIVE PRESSURE (MEAN VALUES OF FIVE TRIAL RUNS FOR EACH DRESSING LENGTH ON A HEALTHY VOLUNTEER ).

\begin{tabular}{llll}
\hline $\begin{array}{l}\text { Negative pressure } \\
\text { Dressing length }\end{array}$ & $40 \mathrm{mmHg}$ & $70 \mathrm{mmHg}$ & $100 \mathrm{mmHg}$ \\
\hline $15 \mathrm{~cm}$ & $40 \mathrm{ml}$ & $50 \mathrm{ml}$ & $60 \mathrm{ml}$ \\
$25 \mathrm{~cm}$ & $45 \mathrm{ml}$ & $62 \mathrm{ml}$ & $75 \mathrm{ml}$
\end{tabular}

performed at room temperature $\left(\sim 21-24^{\circ} \mathrm{C}\right)$. The values in centimeters of $\mathrm{H}_{2} \mathrm{O}$ were transformed to millimeters of mercury $(\mathrm{mmHg})$ with the on-line calculator. ${ }^{2}$

Subsequently, the dressing was applied to 10 patients after a lower anterior rectal resection. This pilot study was approved by the Bioethics Committee at the Oncology Center, Gliwice, Poland. All patients have given their written informed consent to participate in the study and receive this type of dressing. The negative pressure of approximately -80 to $-100 \mathrm{mmHg}$ was created with a standard $50 \mathrm{ml}$ syringe connected to the drain. The vacuum dressing was left in place for 3 days, then changed and placed one more time for the next 3 days. We did not observe any adverse effects due to the dressing application. All postoperative wounds healed properly. 18 out of 20 dressings were airtight after 72 hours post-application. The individual in Fig. 1 has given his written informed consent to publish the photographs.

\section{Discussion}

A similar self-made and cost-effective technique for closed-incision NPWT was initially described by Oliver Muensterer and Richard Keijzer, who used vacuum dressing after a single incision pediatric laparoscopic appendectomy $[3$ Gauze $(5 \times 5 \mathrm{~cm})$ used in their study was folded two times and covered with a biooclusive dressing. The air was evacuated with $22-\mathrm{G}$ needle on a $10 \mathrm{ml}$ syringe which was passed subcutaneously from outside the dressing into the gauze. The authors applied a dressing and measured the negative 
pressure by a liquid column. Over five runs, the negative pressure ranged from $-34 \mathrm{mmHg}$ to $-44 \mathrm{mmHg}$. We previously described the use of this technique in larger wounds (i.e. after open appendectomy or ileostomy reversal). However, the size of the wound was still a limit. ${ }^{4}$ Hypothetically, larger wounds could be covered with the technique proposed by Muensterer and Keijzer, but more than one subcutaneous injection should be performed to evacuate excess air and generate adequate negative pressure. It should be emphasized that every additional injection is connected with a higher risk of complications like hematoma formation. Moreover, this type of dressing could be applied only on an anesthetized patient.

The technique we present in the current paper may be used on a wound of every size and almost in any location. Application is painless so it could be reapplied after 3 days or when the dressing depressurizes. With this method, we are able to create negative pressure lower than $-100 \mathrm{mmHg}$ (similar to the level produced by commercially available, pump-activated vacuum dressings). Finally, the dressing is cost-effective as its total prize depends on the type and amount of materials used however it should not exceed $10 \$$. The cost of commercially available negative pressure wound therapy products is usually twenty times higher.

\section{Conclusions}

This simple, self-made dressing for closed-incision Negative Pressure Therapy is a safe and cost-effective alternative for commercially available NPWT systems. However future studies are necessary to confirm its noninferiority to other forms of NPWT.

\section{REFERENCES}

[1] A. Scalise, R. Calamita, C. Tartaglione, M. Pierangeli, E. Bolletta, M. Gioacchini, R. Gesuita, and G. Di Benedetto, "Improving wound healing and preventing surgical site complications of closed surgical incisions: a possible role of incisional negative pressure wound therapy. a systematic review of the literature," International wound journal, vol. 13 , no. 6 , pp. 1260-1281, 2016

[2] "Convert cmh2o to mmhg - conversion of measurement units," https: //www.convertunits.com/from/cmH2O/to/mmHg accessed: 2020-03-31.

[3] O. J. Muensterer and R. Keijzer, "A simple vacuum dressing reduces the wound infection rate of single-incision pediatric endosurgical appendectomy," JSLS: Journal of the Society of Laparoendoscopic Surgeons, vol. 15 , no. 2, p. $147,2011$.

[4] D. A. Walczak, M. Wojtyniak, P. W. Trzeciak, D. Pawełczak, and Z. Pasieka, "A simple and low-cost technique for closed incision negative-pressure therapy," Negative Pressure Wound Therapy Journal, vol. 4, no. 1, pp. 12-13, 2017. 